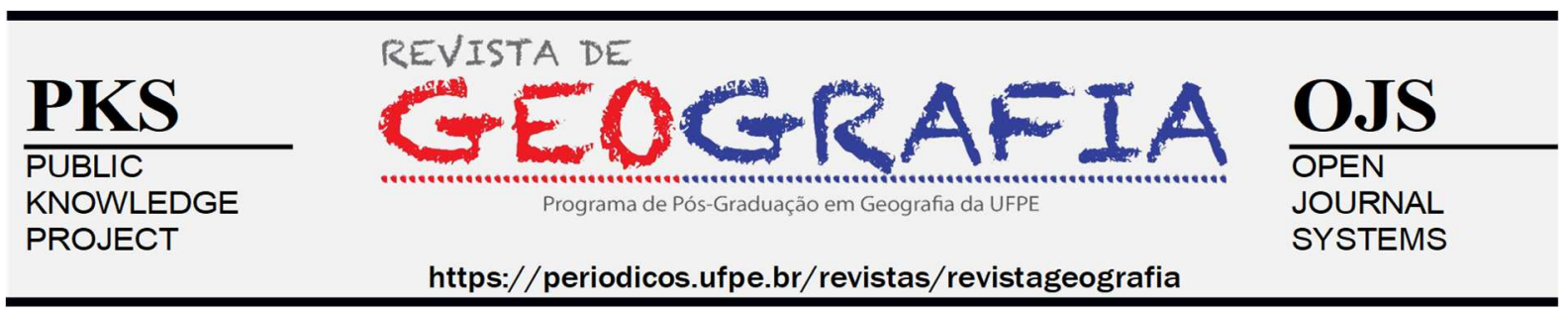

\title{
A INCLUSÃO DE CATADORES NA GESTÃO DE RESÍDUOS SÓLIDOS NOS MUNICÍPIOS PARANAENSES DE ASSIS CHATEAUBRIAND E PALOTINA
}

\author{
Adrielly Grava Costa ${ }^{1}$, Fabio de Oliveira Neves ${ }^{2}$ \\ ${ }^{1}$ Mestre em Geografia pela Universidade Estadual do Oeste do Paraná (Unioeste), prof.adrielly@hotmail.com, \\ http://orcid.org/0000-0002-4032-5585 \\ 2 Doutor em Geografia, Professor do Programa de Pós-Graduação em Geografia da Universidade Estadual do \\ Oeste do Paraná (Unioeste), fabio.neves@ unioeste.br, http://orcid.org/0000-0002-5439-627X
}

Artigo recebido em 28/10/2020 e aceito em 29/04/2021

\begin{abstract}
RESUMO
A inclusão dos catadores aos sistemas formais de recuperação de resíduos é uma prática crescente nas cidades latino-americanas. Neste artigo, objetivou-se o estudo da inclusão de catadores na gestão oficial de resíduos sólidos em dois municípios paranaenses: Assis Chateaubriand e Palotina. O método comparativo utilizado compõe-se de levantamento e tabulação de dados sobre a gestão de resíduos sólidos, pesquisa de campo com observação direta e realização de entrevistas semiestruturadas. Os resultados demonstram diferenças entre os municípios que provém não exatamente da vontade política dos gestores, mas de outras razões, como a ação pública para dar suporte e buscar melhorias das condições da gestão dos resíduos sólidos.
\end{abstract}

Palavras-chave: Rudologia; associação de catadores; reciclagem; coleta seletiva; Oeste Paranaense.

\section{INCLUSION OF WASTE-PICKERS IN SOLID WASTE MANAGEMENT SYSTEMS IN ASSIS CHATEAUBRIAND AND PALOTINA MUNICIPALITIES, PARANA STATE, BRAZIL}

\begin{abstract}
The inclusion of waste-pickers in the formal system of waste recovery is a growing practice in Latin American cities. In this article, we studied the inclusion of waste-pickers in official waste management systems in two municipalities in Parana State, Brazil: Assis Chateaubriand and Palotina. The comparative method involves waste management data collection and tabulation, fieldwork using direct observation and semi-structured interviews. The results show that the differences between the municipalities derive not from the political will of governments, but from other reasons as the public action to support and improve the conditions of the waste management system.
\end{abstract}

Keywords: Rudology; waste-pickers' association; recycling; selective collection. West of Paraná State. 


\section{INCLUSIÓN DE CARTONEROS EN LA GESTIÓN DE RESIDUOS SÓLIDOS EN LAS MUNICIPALIDADES DE ASSIS CHATEAUBRIAND Y PALOTINA, ESTADO DE PARANA, BRASIL}

\section{RESUMEN}

La inclusión de los cartoneros en los sistemas formales de recollección de residuos es una practica creciente en Latinoamérica. En este artículo se estudia la inclusión de los cartoneros en la gestión de residuos en dos municipalidades del Estado de Parana, Brasil: Assis Chateaubriand e Palotina. El método comparativo utilizado se compone de levantamiento y tabulación de datos acerca de la gestión de los residuos sólidos, investigación de campo con observación directa y realización de entrevistas semiestructuradas. Los resultados muestran que las diferencias entre las municipalidades no provienen exactamente de la voluntad política de gobiernos, pero por otras razones, como la acción publica para el apoyo y buscar mejoras en las condiciones de la gestión de los residuos.

Palabras-Clave: Rudologia; asociación de cartoneros; reciclagem; colecta selectiva; Oeste del Estado de Parana.

\section{INTRODUÇÃO}

A Política Nacional dos Resíduos Sólidos (PNRS) incentiva a gestão compartilhada entre o Estado e agentes socioeconômicos por meio tanto da delegação de serviços a empresas privadas, quanto da integração de catadores nos programas oficiais de coleta seletiva e reciclagem (BRASIL, 2010). Para se integrarem à gestão municipal dos resíduos sólidos, os catadores organizam-se em associações e cooperativas para poder firmar contratos com as prefeituras e assumir o serviço de coleta seletiva municipal e/ou deixar as ruas e passar a ter um local específico de trabalho (os galpões de triagem de materiais recicláveis).

Não existe uma única forma de integração dos catadores na gestão "oficial” dos resíduos sólidos. Cada município define como ocorre essa integração, gerando um quadro diversificado de políticas e experiências locais. As experiências das metrópoles e grandes cidades brasileiras na integração dos catadores são intensamente estudadas e publicizadas. Entretanto, uma lacuna existe no estudo dessas experiências em municípios de pequeno porte populacional que, apesar da menor dimensão da produção, também enfrentam problemas de destinação final e reciclagem dos resíduos sólidos.

A fim de contribuir para preencher essa lacuna, objetivou-se nesta pesquisa analisar a integração de catadores na gestão municipal dos resíduos sólidos em dois municípios de pequeno porte populacional: Assis Chateaubriand e Palotina, ambos localizados na mesorregião Oeste Paranaense. A escolha desses municípios foi definida, por um lado, pela vivência e prévia observação da questão dos catadores pela primeira autora e, por outro, em características 
semelhantes dos municípios, como mesma faixa populacional, uma economia atrelada ao agronegócio e a proximidade geográfica entre eles, o que possibilita uma comparação em condições não tão díspares. Esta pesquisa também resultou em uma dissertação de mestrado defendida no Programa de Pós-graduação em Geografia da Universidade Estadual do Oeste do Paraná (Unioeste) do Campus de Marechal Cândido Rondon.

O método comparativo utilizado nesta pesquisa serviu-se da análise de dados provenientes das prefeituras e do Sistema Nacional de Informações sobre Saneamento (SNIS). Na pesquisa de campo, foram realizadas entrevistas semiestruturadas aplicadas a representantes de associações de catadores, funcionários do poder público local, funcionário de empresa privada e uma promotora de justiça. O intervalo de tempo da pesquisa foi definido entre 2003, ano de formação da primeira associação de catadores em um desses municípios (Palotina), até 2017, ano de conclusão da pesquisa de mestrado.

Este artigo se enquadra no subcampo da Rudologia ou "ciência dos resíduos", inspirada pelo geógrafo francês Jean Gouhier que atentou para as potencialidades do estudo dos resíduos como o inverso do palco econômico e social comumente privilegiado pela ciência geográfica (GOUHIER, 2000). Trata-se, portanto, de uma contribuição à agenda da geografia urbana e, ao mesmo tempo, ambiental.

\section{PLANEJAMENTO E GESTÃo DE RESÍDUOS SÓlidOS: O DESCOMPASSO ENTRE A REGULAMENTAÇÃO E A REALIDADE DOS MUNICÍPIOS}

Planejamento e gestão são elementos distintos de uma mesma realidade: o primeiro se remete ao futuro, a objetivos e metas para um setor; enquanto ao segundo cabe resolver os problemas do presente e atender os diferentes interesses envolvidos. Não são termos/atividades concorrentes, mas complementares: o planejamento prepara para as condições de gestão futura e a gestão é a efetivação das condições resultantes do planejamento feito no passado (SOUZA, 2002).

A PNRS (Lei 12.305/2010) e o Plano Nacional dos Resíduos Sólidos são os instrumentos norteadores do planejamento e da gestão desse setor no Brasil. Embora as competências sobre o planejamento e a gestão dos resíduos sólidos se distribuam entre os entes federativos (União, estados e municípios), é ao poder público local que cabe dar destinação adequada aos resíduos produzidos em seu território (BRASIL, 2010). 
O resíduo sólido urbano é classificado como um resíduo municipal, de responsabilidade do poder público local (NEVES, 2013). O município deve executar ou delegar a um prestador de serviço privado as distintas etapas de gestão dos resíduos (coleta, transporte, transbordo, tratamento e destinação final). Atender a PNRS é um desafio para os municípios: serviços diferenciados para a coleta de resíduos especiais (como os de saúde), geram custos adicionais e resistência das prefeituras; mesmo quando existem tecnologias para o tratamento dos diferentes tipos de resíduos, não há garantia de que estas sejam aplicadas (IKUTA, 2010). Há, portanto, um descompasso entre o que exige a PNRS e as realidades técnicas e financeiras dos municípios.

A escolha do tipo de tratamento adequado depende principalmente do tipo de resíduo e da quantidade gerada. No entanto, outros fatores podem influenciar nesta escolha: o custo dos equipamentos necessários, a falta de trabalhadores qualificados para operalos e prestar serviços de manutenção, ou a inexistência de uma política administrativa municipal voltada para a solução dessa questão, são fatores que limitam a instalação dos mecanismos necessários a realização do tratamento de resíduos sólidos. (IKUTA, 2010, p.49-50).

Mesmo com a existência da PNRS desde 2010, os problemas da gestão dos resíduos sólidos se mantêm. A tabela 1 demonstra as unidades de destinação final no Brasil em 2017. Somente aterros sanitários são considerados como destinação final ambientalmente adequada, isto é, que minimizam a poluição ambiental pelo tratamento de efluentes e gases (BRASIL, 2010).

Tabela 1. Unidades de destinação final por aterramento no Brasil - 2017.

\begin{tabular}{ll}
\hline Unid. dest. & Qtd. \\
Aterro sanitário & 640 \\
Aterro controlado & 576 \\
Lixão & 1.091 \\
Total & 2.307 \\
\hline
\end{tabular}

Fonte: Sistema Nacional de Informações sobre Saneamento - (BRASIL, 2019).

Org.: os autores, 2018.

Os municípios brasileiros ainda contam majoritariamente com unidades inadequadas como destinação final para os resíduos sólidos (aterros controlados e lixões). A quantidade de aterros sanitários não ultrapassou e ainda está distante dos lixões e aterros controlados: uma diferença de cerca de 1.000 unidades. Diante desse quadro nada alentador, é necessário pensar 
em soluções para trazer eficiência à gestão municipal dos resíduos sólidos: do recurso ao setor privado à integração de catadores para a promoção da separação e da triagem de resíduos recicláveis.

A participação do setor privado na gestão dos resíduos sólidos vem crescendo no Brasil: este superou o setor público na geração de empregos formais diretos, superando 132 mil vagas no ano de 2017 (Tabela 2).

Tabela 2. Empregos formais diretos no Brasil gerados na limpeza urbana segundo setor (2015-2017).

\begin{tabular}{llll}
\hline $\begin{array}{l}\text { Setor } / \\
\text { Ano }\end{array}$ & Público & Privado & Total \\
2015 & 110.536 & 118.780 & 229.316 \\
2016 & 138.536 & 129.754 & 268.290 \\
2017 & 105.566 & 132.516 & 238.082 \\
\hline
\end{tabular}

Fonte: Sistema Nacional de Informações sobre Saneamento - (BRASIL, 2019).

Org.: os autores, 2019.

O setor informal não consta nesses dados, mas atua por meio de atores sociais que realizam a coleta e a comercialização de materiais recicláveis e encarregam-se de dar um destino alternativo a parte dos resíduos sólidos que, de outro modo, iria ser destinada ao aterramento. Os atores informais são responsáveis por parte da gestão dos resíduos sólidos ao atuar nos interstícios do serviço público, mesmo que não sejam reconhecidos pelo Estado (NEVES, 2013).

Os dois setores, o formal e o informal, estão imbricados na reciclagem, etapa conhecida como valorização pós-consumo. Nesta etapa, atuam à montante nas funções de coleta e triagem: catadores informais, associações ou cooperativas de catadores, o poder público local, empresas de coleta de lixo e pequenos sucateiros; à jusante nas funções de transporte e reciclagem: os grandes atravessadores e as indústrias recicladoras. O poder público local tem uma atuação limitada à montante da reciclagem: a coleta seletiva municipal dos resíduos recicláveis "secos" ainda não é efetiva na maioria dos municípios brasileiros (Tabela 3). Entre 2015 e 2017, não há nem mesmo uma evolução linear na quantidade de municípios que ofertam a coleta seletiva. Além disso, a simples constatação da existência da coleta seletiva de materiais recicláveis não garante que sua frequência seja adequada ou realizada em toda a cidade. 
Tabela 3. Existência de coleta seletiva municipal de recicláveis "secos” nos munícios brasileiros (2015-2017).

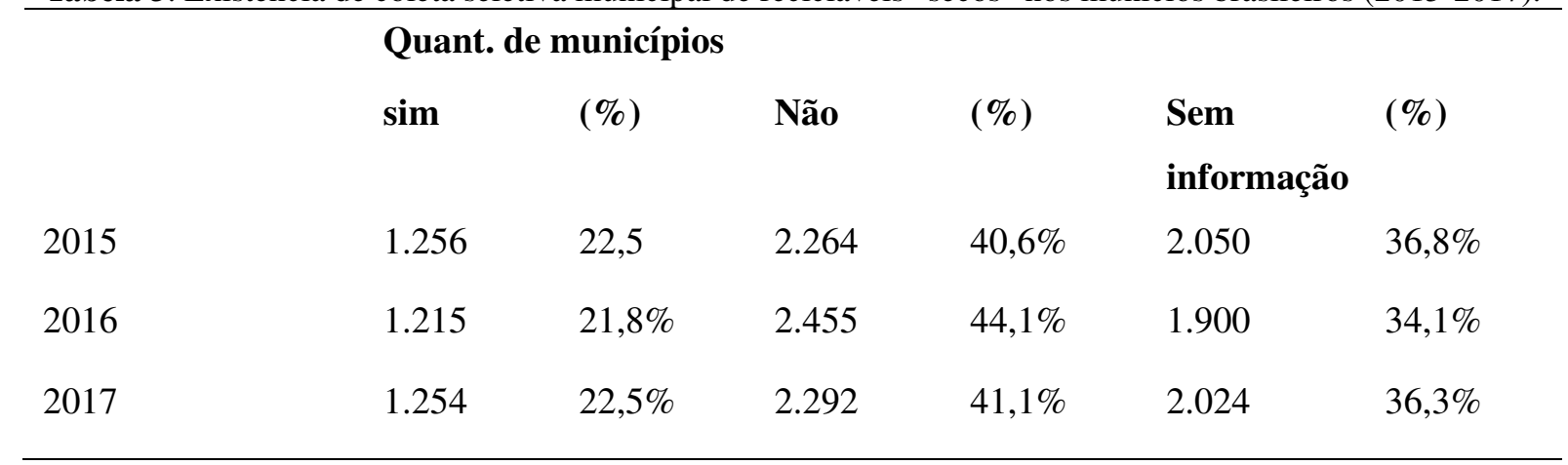

Fonte: Sistema Nacional de Informações sobre Saneamento - (BRASIL, 2019).

Org.: os autores, 2019.

\title{
CATADORES ENQUANTO PARCEIROS NA GESTÃO DOS RESÍDUOS SÓLIDOS
}

As representações negativas sobre o lixo (o imundo, indesejado, sujo) acabam por confundir-se com as representações sobre os próprios catadores, reforçando preconceitos e a invisibilidade destes enquanto agente socioeconômico e (por que não?) ambiental na cidade.

\begin{abstract}
A invisibilidade parece ser "característica em comum" entre os que lidam diretamente com os resíduos produzidos por todos. E, em uma espécie de cegueira coletiva, esta sociedade não enxerga os agentes que todos os dias passam com os carrinhos na porta de sua casa, que coletam suas latinhas de alumínio em grandes eventos ou que trabalham em cooperativas que, possivelmente, não saberia diferenciar de um depósito de ferro-velho. (SALGADO; TEIXEIRA, 2012, p. 74)
\end{abstract}

As condições de trabalho e renda dos catadores são consideravelmente precárias e exigem grandes esforços físicos e psicológicos no cotidiano desses agentes. Os catadores

[...] trabalham com pequenas quantidades de material, sua única opção é vender aos pequenos sucateiros, que em sua maioria, atuam na informalidade e pagam preços muito baixos pelos materiais recicláveis. Esses catadores são obrigados a vender, diariamente, o produto gerado, puxando suas carroças pelas ruas da cidade, uma vez que não têm como estocar o produto. Para muitos, a carroça se torna também o seu local de residência no período noturno. Eles vendem o produto de sua coleta sem nenhum poder de barganha (DEMAJOVORIC; LIMA, 2013, p. 58).

Embora exista há séculos, a profissão de catador veio a ser reconhecida no Brasil somente em 2002 (Portaria n. 397, de 9 de outubro de 2002, do Ministério do Trabalho, sob o Código $\mathrm{n}^{\circ}$ 5.192-05). Este reconhecimento acompanhou não só os processos de integração deste nas gestões municipais de resíduos sólidos, mas também as transformações que subvertem preconceitos e a invisibilidade deste profissional. Atualmente, os catadores "se percebem como realizadores de atividades que promovem a limpeza, e, associada a ela, a preservação do meio ambiente" (MAGALHÃES, 2013, p. 256). Eles possuem "direito ao seu trabalho, tendo 
possibilitado, ainda, uma série de outras conquistas importantes” (MAGALHÃES, 2013, p. 254).

As organizações coletivas de catadores ajudam ao processo de reconhecimento da profissão, promovem a categoria e abrem possibilidades de parceria com o poder público. Existem em duas formas principais: as associações e as cooperativas.

\begin{abstract}
A diferença essencial está na natureza dos dois processos. Enquanto as associações são organizações que têm por finalidade a promoção de assistência social, educacional, cultural, representação política, defesa de interesses de classe, filantropia, as cooperativas têm finalidade essencialmente econômica, seu principal objetivo é viabilizar o negócio produtivo de seus associados junto ao mercado. (CARDOSO, 2014, p. 21).
\end{abstract}

A cooperativa desenvolve atividades fundamentalmente econômicas. Os cooperados são donos do patrimônio e beneficiários dos ganhos: lucros são distribuídos entre eles. As cooperativas foram regulamentadas a partir do art. $4^{\circ}$, Lei $n^{\circ} 5.764$ (BRASIL, 1971), que as define como "sociedades de pessoas, com forma e natureza jurídica próprias, de natureza civil, não sujeitas a falência, constituídas para prestar serviços aos associados, distinguindo-se das demais sociedades".

As associações, por sua vez, foram definidas por meio da Lei $\mathrm{n}^{\circ} 10.406$ (BRASIL, 2002), em seu art. 53: "Constitui-se as associações pela união de pessoas que se organizem para fins não econômicos". Buscam reunir pessoas com objetivos comuns, as quais juntas possam superam as dificuldades e gerar benefícios para o grupo. Associação corresponde a:

[...] qualquer iniciativa formal ou informal que reúne pessoas físicas ou outras sociedades jurídicas com objetivos comuns, visando superar dificuldades e gerar benefícios para os seus associados. Formalmente, qualquer que seja o tipo de associação, pode-se dizer que a associação é uma forma jurídica de legalizar a união de pessoas em torno de necessidades e objetivos comuns. Sua constituição permite a construção de melhores condições do que aquelas que os indivíduos teriam isoladamente para a realização dos seus objetivos. (CARDOSO, 2014, p.07).

As associações têm como princípio o associativismo, ou seja, o pressuposto de que, por meio da união entre indivíduos, podem ser solucionadas questões que dizem respeito à vida em sociedade (CARDOSO, 2014). As associações possuem algumas características:

1. Reunião de duas ou mais pessoas para a realização de objetivos comuns (lembrando que a lei não define o número legal para criar uma associação);

2. Seu patrimônio é constituído pela contribuição dos associados ou de seus membros, por doações, subvenções. Não possui capital social, por isso dificulta a obtenção de financiamento junto às instituições financeiras;

3. Seus fins podem ser alterados pelos associados;

4. Seus associados deliberam livremente; 
5. São entidades do direito privado e não público (CARDOSO, 2014, p.10).

A gestão compartilhada dos resíduos através das parcerias entre poder público e catadores organizados em associações e/ou cooperativas (instituídas pela Lei 12.305) é fundamental na melhoria das condições de trabalho e renda destes. Em geral, as parcerias demandam a disponibilização de estrutura física (galpões, máquinas etc.) e são acompanhadas de projetos para promover o bem-estar social, treinamentos, questão financeira, incentivos para construir, ampliar e reestruturar ambientes e adquirir ferramentas. Pode-se dizer que, por um lado, os catadores são beneficiários de projetos e melhorias nas condições de trabalho e renda e, por outro lado, a prefeitura passa a ter um serviço de baixo custo e que desvia parte do fluxo de resíduos sólidos que iria diretamente ao aterramento.

\footnotetext{
O modelo de gestão compartilhada, que envolve a participação das prefeituras, de grupos organizados de catadores e da comunidade local, propicia benefícios socioambientais e financeiros, ao desviar parcela de resíduos dos aterros sanitários para a reciclagem e contribuir para a geração de renda entre os catadores. (DEMAJOROVIC; LIMA, 2013 p.70).
}

O apoio às organizações de catadores também vem de instituições públicas diversas, como: a Fundação Nacional de Saúde, o Banco Nacional do Desenvolvimento, o Ministério do Desenvolvimento Social, o Ministério do Meio Ambiente, a Caixa Econômica Federal, o Banco do Brasil e a Petrobras. Os recursos provenientes de tais instituições permitem que se invista em diversos segmentos do processo da reciclagem desde infraestrutura, equipamentos como prensas e esteiras, caminhão para coleta, espaço físico de trabalho e na capacitação e profissionalização dos catadores, de modo que possam se tornar prestadores de serviço de coleta seletiva para as prefeituras, serviços comerciais e indústrias (DEMAJOROVIC; LIMA, 2013).

Apesar dos avanços no campo de desenvolvimento das organizações de catadores, os desafios continuam, pois há problemas desde a falta de equipamentos, até problemas na estrutura organizacional da associação ou cooperativa de catadores, o que dificulta a integração e consequentemente a tomada de decisões (DEMAJOROVIC; LIMA, 2013). Por um lado, as organizações de catadores ainda são fortemente dependentes de parcerias com outras instituições que viabilizem seu trabalho e sua continuidade. Por outro lado, a demanda da logística reversa de embalagens e materiais recicláveis depende da consolidação das organizações de catadores. "Do ponto de vista econômico, as parcerias podem ser formas essenciais para garantir a viabilidade da logística reversa prevista na nova lei" 
(DEMAJOROVIC; LIMA, 2013, p. 78). Nesse contexto, aumenta-se o apelo à integração dos catadores nas gestões municipais dos resíduos sólidos. Contudo, esse processo se desenvolve de forma variada e desigual no território, dependendo das políticas e gestores locais. É necessário, portanto, prosseguir para o estudo de realidades específicas para melhor compreender esse processo.

\section{GESTÃO COMPARTILHADA DE RESÍDUOS SÓLIDOS EM ASSIS CHATEAUBRIAND E PALOTINA/PR}

Os municípios de Assis Chateaubriand e Palotina, entretanto, localizados na mesorregião Oeste Paranaense (Figura 1), adotaram a gestão compartilhada dos resíduos sólidos entre poder público e catadores organizados e empresas privadas (a última no caso de Palotina).

Figura 1. Mapa de localização da área de estudo.

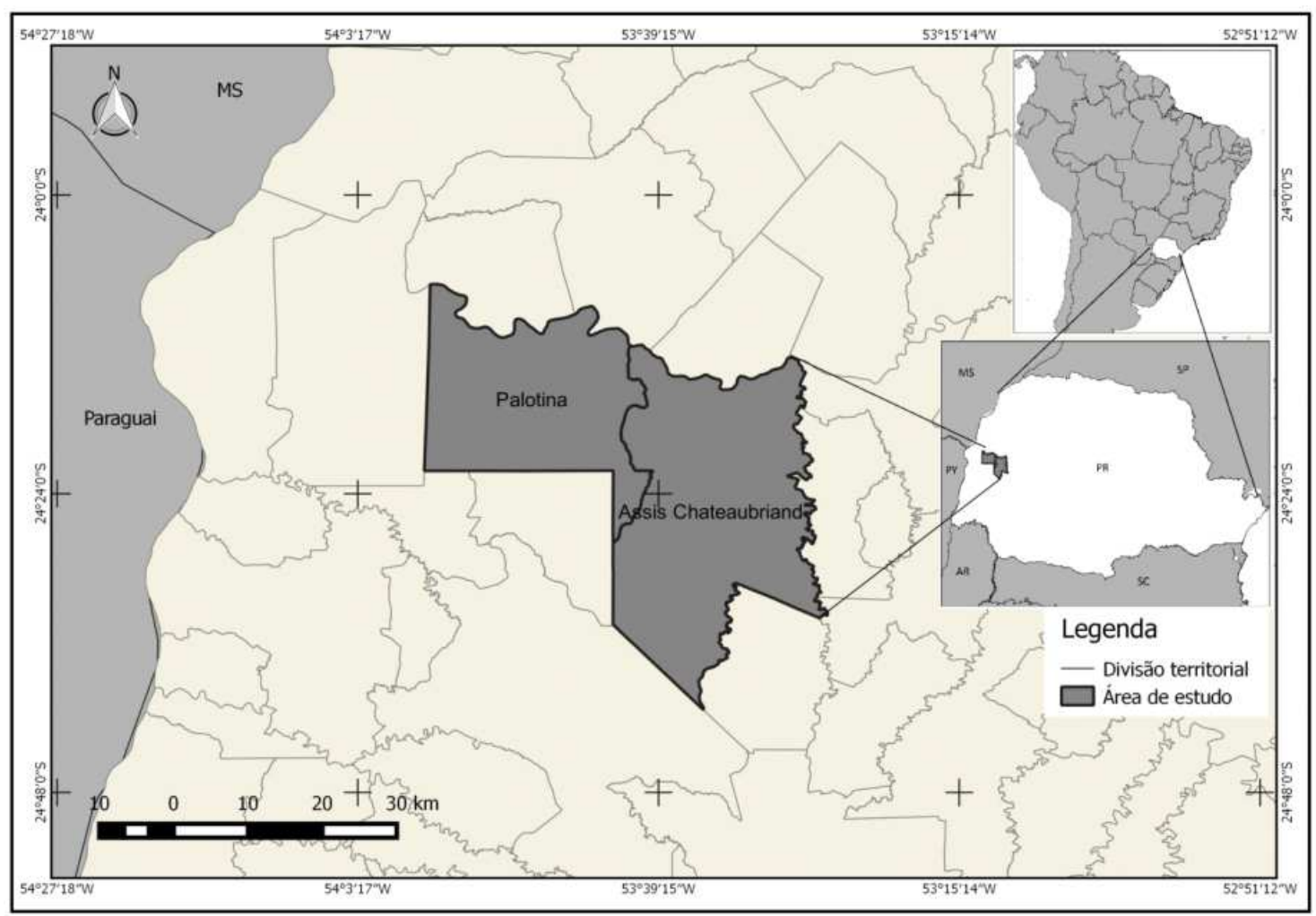

Org.: os autores, 2017.

A figura 2 apresenta o fluxograma dos resíduos sólidos urbanos nos dois municípios, indicando similaridade: o principal fluxo (seta contínua) é direcionado ao aterramento, provém da coleta comum, limpeza pública de ruas e áreas comuns e rejeito que sai dos galpões de 
triagem; o fluxo secundário (seta tracejada) é direcionado ao exterior do sistema, inicia-se com a coleta seletiva, passando em seguida pela triagem nos galpões e posterior venda para as indústrias recicladoras.

Figura 2. Fluxograma de resíduos sólidos urbanos (Assis Chateaubriand e Palotina, 2017).

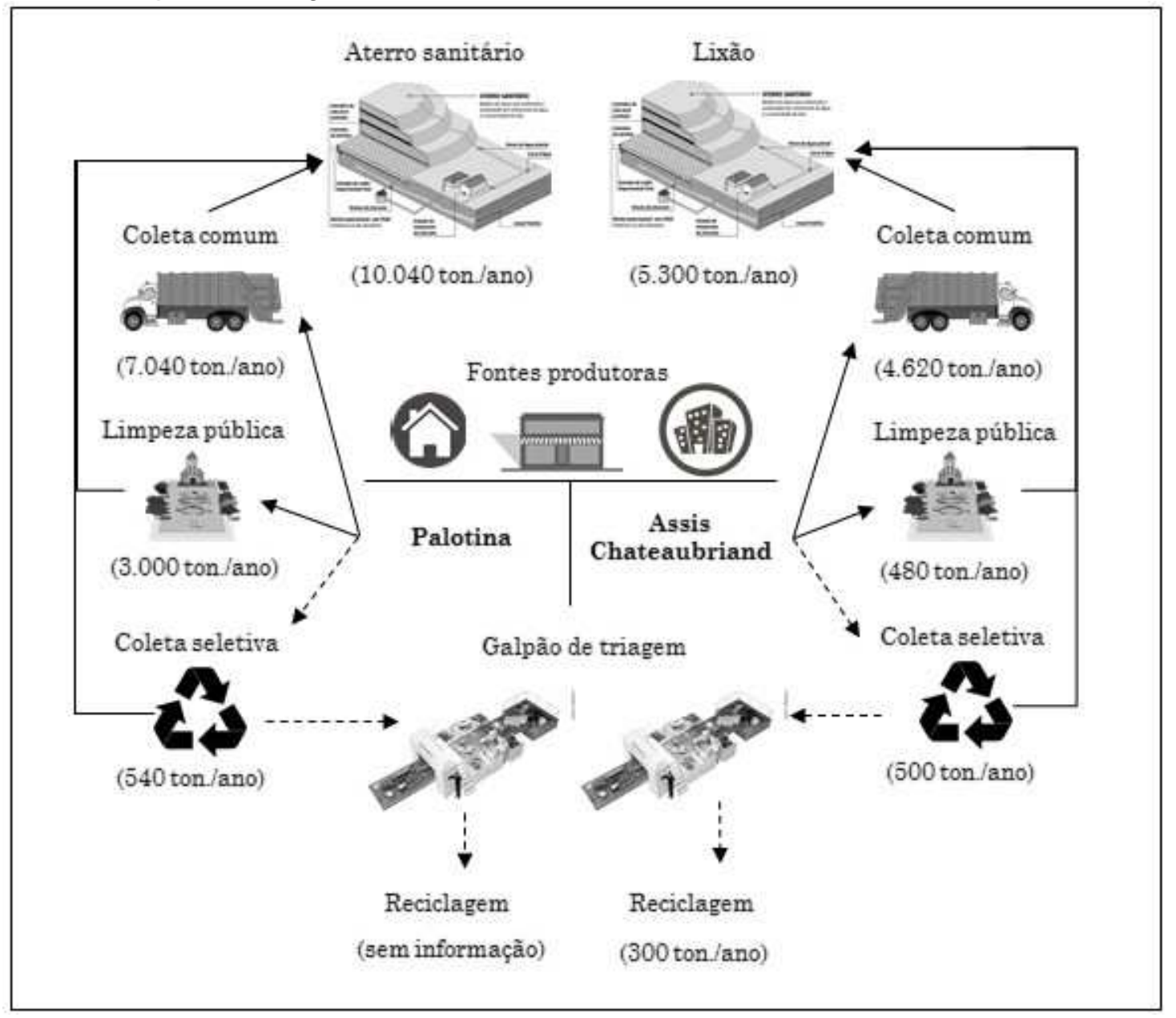

Fonte: Sistema Nacional de Informações sobre Saneamento - (BRASIL, 2019). Org.: os autores.

Em ambos os municípios, a coleta do lixo é assegurada a 100\% dos habitantes urbanos, enquanto a média brasileira é de 98,8\% (BRASIL, 2019). Apesar de ter maior população, Assis Chateaubriand (29.013 hab., IBGE, 2019) produz e coleta cerca da metade de resíduos que Palotina (24.646 hab., IBGE, 2019). Esse dado corrobora com a importância do valor adicionado bruto (VAB) (valor que cada setor da economia acresce ao que foi produzido em um território), já que Palotina produz mais riqueza (1,7 bilhões de reais, contra 1 bilhão de Assis Chateaubriand) e consequentemente mais resíduos (IBGE, 2019). 
A taxa de coleta de materiais recicláveis em relação ao total do lixo coletado é de 5,37\% do lixo total em Palotina e 9,43\% em Assis Chateaubriand. Mesmo com a diferença nessa taxa, os dois municípios coletam uma quantidade praticamente equivalente de materiais potencialmente recicláveis (cerca de 500 toneladas/ano).

O fluxo direcionado ao lixão (após a coleta comum, limpeza urbana e rejeitos das centrais de triagem) é de 94,6\% em Assis Chateaubriand, enquanto em Palotina estima-se que este corresponda a 98\% (o cálculo deste percentual se encontra prejudicado neste último município, pois não é declarada a quantidade de rejeitos que sai do galpão de triagem em direção ao aterro sanitário), o que indica a necessidade do aprimoramento da coleta seletiva em ambos.

A destinação final é classificada como ambientalmente adequada em Palotina (aterro sanitário), mas não em Assis Chateaubriand, onde ainda existe o lixão municipal (este passou por um processo de readaptação em 2011 para garantir as condições de aterro controlado, mas a situação regrediu de volta para condições próximas às anteriores) (Figura 3).

Figura 3. Lixão de Assis Chateaubriand.
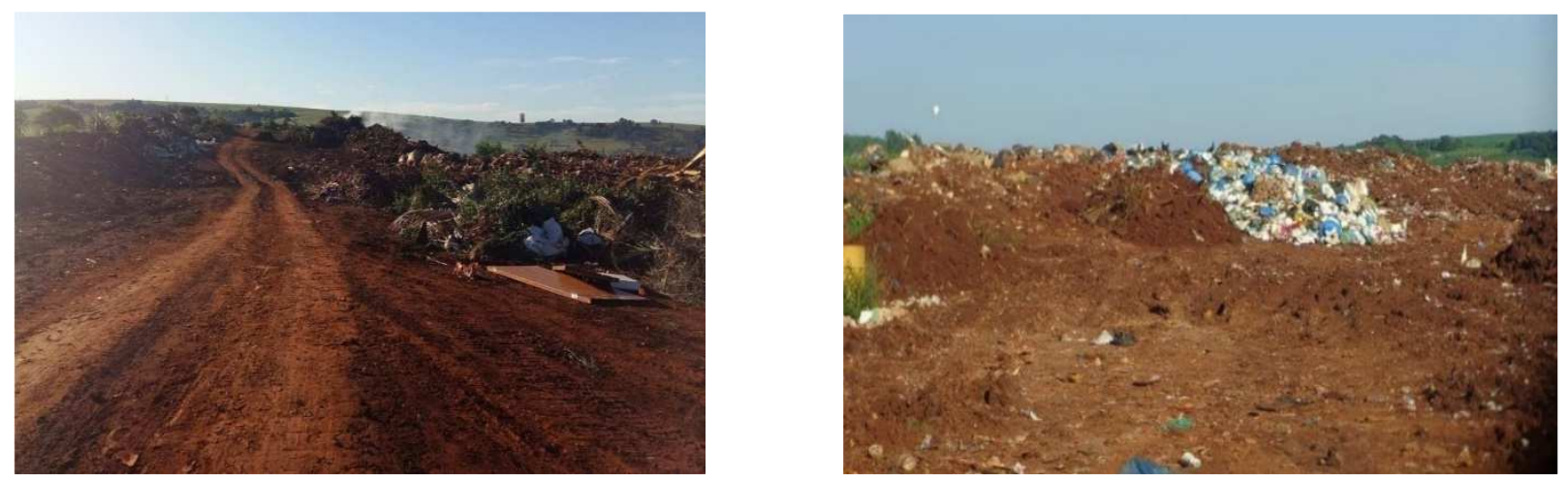

Fotos: os autores, 2016.

Em observação in loco, realizada em 2016, caracterizamos as unidades de destinação dos municípios em questão. Destaca-se negativamente a queima de resíduos no lixão de Assis Chateaubriand. A ausência de drenagem e tratamento de gases e de efluentes, assim como a falta de manta de impermeabilização e o recobrimento eventual do lixo confirmam as condições de vazadouro à céu aberto (lixão) neste município. Contrariamente, em Palotina, as condições de operação (notadamente o recobrimento sistemático diário, a drenagem de efluentes e gases) garantiram a renovação de sua licença de operação junto ao Instituto Ambiental do Paraná- IAP (n. 19144) como aterro sanitário. 
Com relação ao componente financeiro nos dois municípios, a receita com as taxas de lixo é insuficiente para cobrir as despesas de coleta convencional e seletiva, manutenção do galpão de triagem e serviços na unidade de disposição final (Tabela 4). Os custos dependem, portanto, de transferências do orçamento geral do município. Os dados de Palotina apresentaram claramente uma inconsistência, pois foram repetidos durante cinco anos.

Tabela 4. Receitas e despesas com os serviços de limpeza urbana (em reais).

\begin{tabular}{|c|c|c|c|c|}
\hline Município/ & Assis Chateaubrianc & & Palotina & \\
\hline ano & Receita arrecadada & $\begin{array}{l}\text { Despesa total } \\
(\mathrm{R} \$)\end{array}$ & Receita arrecadada & $\begin{array}{l}\text { Despesa } \\
(\mathrm{R} \$)\end{array}$ \\
\hline 2011 & $697.787,35$ & Não informada & $985.810,00$ & Não informada \\
\hline 2012 & $515.406,00$ & $1.863 .800,00$ & $913.203,32$ & Não informada \\
\hline 2013 & $794.182,12$ & $838.079,20$ & $1.198 .119,00$ & $2.961 .004,00$ \\
\hline 2014 & Não informada & Não informada & $1.198 .119,00$ & $2.961 .004,00$ \\
\hline 2015 & $697.000,00$ & $1.345 .766,52$ & $1.198 .119,00$ & $2.961 .004,00$ \\
\hline 2016 & $787.000,00$ & $1.858 .999,31$ & $1.198 .119,00$ & $2.961 .004,00$ \\
\hline 2017 & $1.047 .000,00$ & $1.981 .289,01$ & $1.198 .119,00$ & $2.961 .004,00$ \\
\hline
\end{tabular}

Fonte: Sistema Nacional de Informações sobre Saneamento - Série Histórica; Prefeituras municipais. Org.: o Autor, 2017.

Considerando, portanto, o fluxo de resíduos sólidos, a relação entre despesas e receitas e a situação de destinação final (apresentados acima), torna-se evidente a necessidade de melhorias no sistema de gestão de resíduos em ambos os municípios. É preciso questionar-se qual é o papel dos catadores na gestão municipal dos resíduos, o que é apresentado a seguir.

\section{Como atuam os catadores organizados de Palotina e de Assis Chateaubriand?}

Nos municípios analisados, os catadores organizaram-se em associações, mas não chegaram a formar cooperativas, o que indica um processo de organização que ainda não se completou. A formação de uma cooperativa indica o estabelecimento de uma entidade econômica/pessoa jurídica que pode inclusive demandar crédito para investimentos. Isso, normalmente, não acontece com as associações que dependem mais diretamente de doações de equipamentos, máquinas, entre outros objetos de instituições parceiras. 
Em Palotina, a Associação dos Agentes Ambientais e de Reciclagem Palotina Preserva (APAVA) foi criada em 2003: possui 24 associados (seis homens e dezoito mulheres, em 2016), e, em sua maioria, é composta de pessoas que anteriormente não trabalhavam com a catação, isto é, não eram catadores de rua. O trabalho é quase exclusivamente realizado no interior do galpão de triagem, pois a coleta seletiva é realizada por empresa privada contratada pela prefeitura (exceto a coleta de materiais recicláveis das empresas parceiras que é realizada pela própria associação).

Em Assis Chateaubriand, a associação é mais recentemente: a Associação de Catadores de Materiais Recicláveis (ACAMAR) foi criada em 2011. Conta com 18 associados (dez mulheres e oito homens, em 2016) que exercem suas atividades no barracão de triagem. Os catadores têm dois tipos de trabalho: o da triagem e o da coleta seletiva, pois, diferentemente do caso anterior, são os próprios que a realizam.

A existência dessas associações é diretamente dependente das prefeituras. Na figura 4, demonstram-se o antigo e o atual galpão da APAVA em Palotina. O primeiro esteve em operação entre 2003 (ano de fundação da APAVA) e 2012. As instalações eram precárias, dentro da cidade e envolto por residências. A situação gerava diversos conflitos e reclamações da vizinhança junto à prefeitura (segundo entrevistado). Atualmente, a APAVA está sediada em uma estrutura construída pela prefeitura de aproximadamente $600 \mathrm{~m}^{2}$, com galpão, banheiros, cozinha e escritório.

Figura 4. Antiga e atual instalação da APAVA.
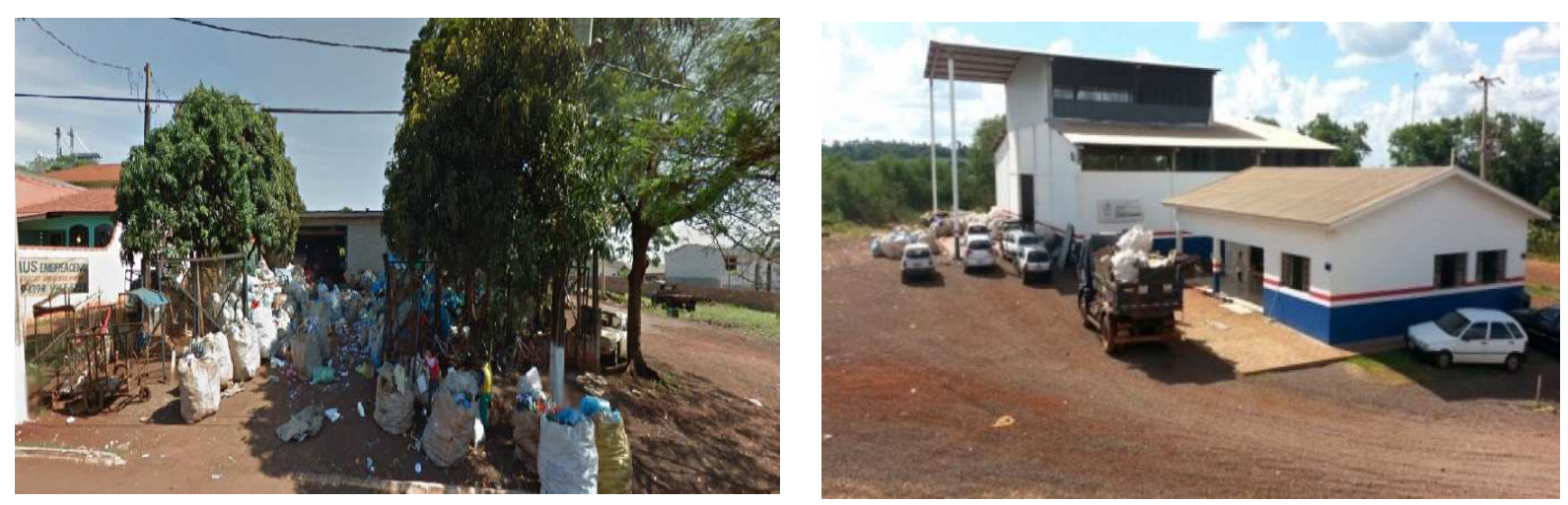

Fotos: Dorival Canhete, 2012; os autores, 2016.

Os associados possuem horários fixos de trabalho: segunda a sexta, das 8 às 17 horas. A renda média mensal é de $\mathrm{R} \$ 1.600,00$ (dado das planilhas de pagamento da associação). Há um funcionário da prefeitura que auxilia no processo de venda, no pagamento dos catadores e 
faz o recolhimento do tributo da previdência, o que demonstra certa dependência da associação até para a organização básica do trabalho e dos pagamentos.

Em Assis Chateaubriand, a estrutura e as condições de trabalho são comparativamente piores. Enquanto um grupo de catadores trabalha na rua coletando os materiais, outro grupo está no barracão fazendo a triagem e negociando os valores de venda dos materiais. O barracão apresenta deficiências de estrutura, organização interna e aos equipamentos disponíveis que afetam a eficácia do trabalho: o material separado em bags ou grandes sacos é constantemente molhado quando há chuvas (embora tenha cobertura, não há paredes laterais, apenas colunas de sustentação); não há esteira de separação (o que dificulta e torna mais lenta a triagem); não se dispõe de balança (a associação encontra-se sujeita à pesagem que realizam os próprios compradores, o que fragiliza seu poder de negociação) (Figura 5).

Figura 5. Carência de equipamentos e estrutura adequada no galpão da ACAMAR

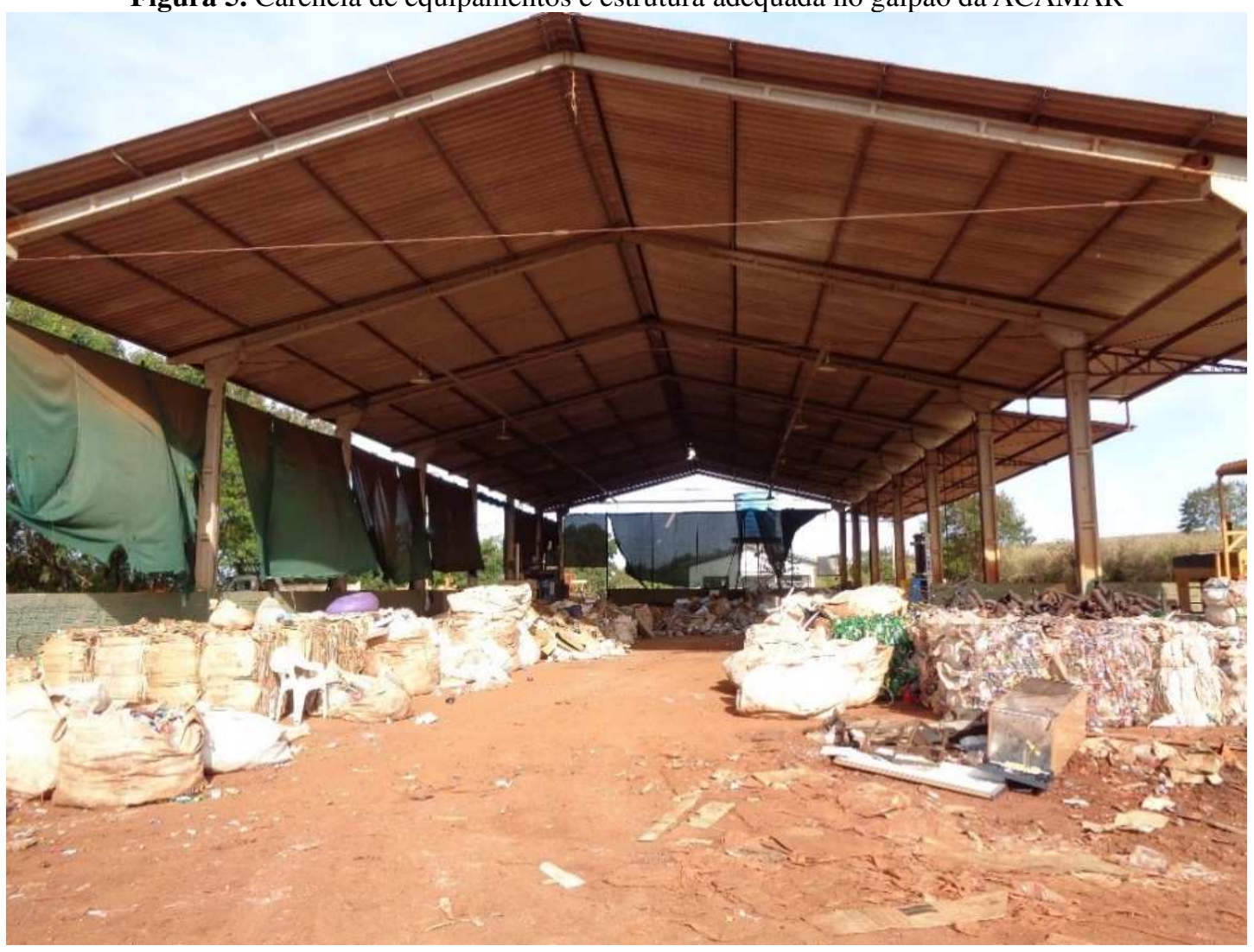

Foto: os autores, 2017.

A comercialização é realizada em um intervalo de vinte a trinta dias e o valor da venda é dividido igualmente entre os associados, gerando uma renda de aproximadamente $\mathrm{R} \$ 1.000,00$ para cada um, segundo a secretaria da ACAMAR (menor, portanto, do que a de Palotina). Quem Costa; Neves, 2021 
realiza a comercialização, venda e o rateio são os próprios catadores, que entram em contato com os compradores e negociam os valores e formas de pagamento.

\section{A “vontade política” e a Ação Civil Pública fazendo a diferença}

Já foi afirmado neste texto que há melhores condições de infraestrutura e trabalho em Palotina, atribuí-la à "vontade política" é uma meia verdade. Neste município, as condições de trabalho dos catadores tiveram uma reviravolta com a intervenção do Ministério Público do Estado do Paraná (MPPR), representado pela promotora de justiça Dra. Cristiane Aparecida Ramos, por meio de uma Ação Civil Pública nº59/2008 que instituiu o termo de ajuste de conduta do município na gestão dos resíduos sólidos. A partir da ação do MPPR, o município se comprometeu a: manter em condições adequadas o barracão de triagem (em situação inadequada até 2012); continuar com a coleta seletiva; promover campanhas educativas e a inclusão social dos catadores; e fornecer meios para que a associação pudesse se manter e desenvolver as suas atividades, com formação continuada e assessoria técnica.

Entre as medidas adotadas, após o termo de ajuste de conduta, estavam a de destinar os catadores para o novo galpão e apoiar a associação. Desta forma, os catadores receberam incentivos como: a concessão do uso do galpão, despesas pagas de água, luz, transporte da cidade até o local de trabalho, entre outros. O processo de integração dos catadores dependeu, portanto, do envolvimento do MPPR para ocorrer em melhores condições.

Em Assis Chateaubriand, houve um primeiro programa de integração criado pela prefeitura que fracassou. Nesse, os catadores eram chamados de "agentes azuis" e receberam: uniforme, material de segurança e carrinho. Os catadores deveriam seguir as regras e horários de trabalho, bem como informar a destinação do material coletado. Os resultados não foram exitosos, pois muitos catadores não se adequavam às regras, extraviavam o material vendendo para sucateiros e atravessadores não autorizados pela prefeitura e, desta forma, foram se desvinculando do projeto (segundo os próprios catadores entrevistados).

A prefeitura municipal apoiou, então, a formação da associação de catadores (ACAMAR), oferecendo-lhes o barracão de triagem, materiais para trabalho, além das despesas pagas (contas de água, luz, alimentação, manutenção dos caminhões de coleta, máquinas e transporte até o local de trabalho). Em contrapartida, os catadores deveriam prestar conta das 
atividades desenvolvidas, bem como de todo o processo de triagem do material, desde a coleta até a venda e o pagamento de todos os associados.

A ACAMAR não recebe auxílio de outro órgão a não ser da prefeitura de Assis Chateaubriand. A prefeitura municipal disponibiliza um funcionário para auxiliá-los em questões técnicas e financeiras, destina cestas básicas aos catadores, roupas doadas por campanhas sociais ("Campanha do Agasalho"), entre outras atividades de assistência social que acontecem no decorrer do ano.

Em Assis Chateaubriand, a coleta seletiva municipal - executada pelos catadores - é recente (2014). Em 2017, coletou-se 9,43\% de materiais recicláveis no lixo doméstico municipal, ou seja, 500 toneladas, com um aproveitamento de $60 \%$ do que chega ao galpão de triagem. Em Palotina, coletou-se 5,37\%, ou seja, 540 toneladas. Como os dados de geração de rejeitos de Palotina não foram declarados no Sistema Nacional de Informações sobre Saneamento, não é possível apontar a maior eficiência de um ou outro.

É possível confirmar, entretanto, que há uma evolução em Palotina a partir da intervenção do Ministério Público no setor. De 2012 a 2015, a venda de materiais recicláveis pela associação teve um aumento considerável de aproximadamente $22.000 \mathrm{~kg} / \mathrm{mês}$ (Tabela 5), resultante do trabalho dos catadores associados acrescido das campanhas de educação ambiental que se realizaram neste período.

Tabela 5. Média mensal de materiais recicláveis vendidos pela APAVA.

\begin{tabular}{lllll}
\hline Ano & 2012 & 2013 & 2014 & 2015 \\
Venda & $28.610,7$ & $38.561,7$ & $49.566,4$ & $50.378,5$ \\
(kg. /mês) & & & & \\
\hline
\end{tabular}

Fonte: APAVA, 2012-2015.

Org.: os autores, 2016.

Com relação aos fluxos de materiais recicláveis captados pelos catadores informais, não se tem estimativas de quantidade e nem do número de agentes informais envolvidos. Conforme os entrevistados, os informais não se associam porque preferem continuar na informalidade sem cumprir as regras e horários definidos na associação.

É reconhecido que o processo de integração dos catadores à gestão oficial dos resíduos em cidades latino-americanas não eliminou a "catação" informal e, conjuntamente, 
mantém/gera conflitos entre os informais e o sistema de gestão (catadores formalizados e empresas prestadores de serviço) (DURAND; NEVES, 2019).

\section{CONSIDERAÇÕES FINAIS}

A integração dos catadores na gestão dos resíduos sólidos nos municípios de Assis Chateaubriand e Palotina evidencia uma dependência persistente das associações dos catadores em relação às prefeituras. Concluímos que se trata mais de apoio e auxílio a um grupo socialmente/economicamente frágil do que uma verdadeira parceria. A visão central não parece a de simplesmente aprimorar a triagem de recicláveis, mas a de prestar auxílio social, isto é, muito mais uma ação de cunho social do que ambiental. Isso se confirma pela existência das associações com caráter mais de assistência social e defesa de interesses do grupo do que de empreendimento econômico (o que ocorre majoritariamente a partir da criação de cooperativas de catadores).

A fiscalização do Ministério Público do Paraná sobre as ações realizadas em Palotina contribuiu de maneira relevante para que os catadores tivessem progressos na quantidade de materiais recicláveis, nas condições de trabalho e na renda em relação àqueles que atuam em Assis Chateaubriand. Mais do que "vontade política" parece que a pressão da sociedade e mecanismos jurídicos que, nos casos analisados, acabaram interferindo no diferencial da situação da integração dos catadores e na gestão dos resíduos nos dois municípios analisados. Por fim, acreditamos que estas conclusões acabam convidando a novas pesquisas se debruçarem sobre as ações de outras instituições, para além das prefeituras, no desenvolvimento e consolidação das integrações de organizações de catadores na gestão pública dos resíduos sólidos.

\section{AGRADECIMENTOS}

O presente trabalho foi realizado com apoio da Coordenação de Aperfeiçoamento de Pessoal de Nível Superior -Brasil (CAPES) - Código de Financiamento 001. 


\section{REFERÊNCIAS}

BRASIL. Lei no 5764, de 16 de dezembro de 1971. Define a Política Nacional de Cooperativismo, institui o regime jurídico das sociedades cooperativas, e dá outras providências.

BRASIL. Lei $\mathbf{n}^{\circ} \mathbf{1 0 . 4 0 6}$, de 10 de janeiro de 2002. Institui o Código Civil.

BRASIL. Lei $\mathbf{n}^{\circ}$ 12.305, de 2 de agosto de 2010. Institui a Política Nacional de Resíduos Sólidos e dá outras providências.

BRASIL. Ministério do Desenvolvimento Regional. Secretaria Nacional de Saneamento SNS. Sistema Nacional de Informações sobre Saneamento: Diagnóstico do Manejo de Resíduos Sólidos Urbanos - 2017. Brasília, DF, Brasil, 2019.

CARDOSO, U. C. Associação. Brasília, DF: Sebrae, 2014.

DEMAJOROVIC, J; LIMA, M.. Cadeia de reciclagem: um olhar para os catadores. São Paulo: Editora Senac, Edições Sesc SP, 2013.

DURAND, M; NEVES, F. O. L'intégration des cueilleurs de déchets latino-américains ou la création d'une nouvelle marge. Echogéo, n. 47, p. 1-18, 2019. Disponível em: http://journals.openedition.org/echogeo/16894. Acesso em: 10 jan. 2020.

GOUHIER, J. Au-delà du déchet, le territoire de qualité: manuel de rudologie. Le Havre: Presses Universitaire de Rouen et du Havre, 2000.

IKUTA, F. A. Resíduos sólidos urbanos no Pontal do Paranapanema: coleta seletiva e organização de catadores. Caderno Prudentino de Geografia, v. 32, n. 2, p. 235-260, 2010.

INSTITUTO BRASILEIRO DE GEOGRAFIA E ESTATÍSTICA (IBGE). (2019). IBGE

Cidades. 2019. Disponível em: https://cidades.ibge.gov.br. Acesso em: 2 jan. 2019.

MAGALHÃES, B. J. Catadores de materiais recicláveis, consumo e valorização social. Revista da UFMG, v. 20, n.1, p. 246-265, 2013.

SALGADO, G. M.; TEIXEIRA, T. F. Catadores(as) e a metrópole: identidade, processo e luta. São Paulo: s.n., 2012.

SOUZA, M. L. Mudar a cidade. Uma introdução crítica ao planejamento e à gestão urbanos. Rio de Janeiro: Bertrand Brasil, 2002. 